\title{
História, eventos e narrativa: incidentes e cultura do quotidiano*1
}

\author{
History, events and narrative: \\ incidents and daily culture
}

\begin{abstract}
ROBERT DARNTON
History Department, Princeton University 129 Dickinson Hall, Princeton University, Princeton

NJ 08544-1017 - USA

darnton@princeton.edu
\end{abstract}

Un incident, une bêtise,

La mort de votre jument grise

Paul Misraki - Tout va très bien Madame la marquise

RESUMO Escândalos, massacres, desabamentos, seqüestros: muitos temas que eram associados a tablóides e romances policiais têm sido objeto de um grande número de livros de história, que vêm ganhando espaço privilegiado nas estantes das livrarias. Trata-se do despontar de um novo gênero historiográfico, o das "análises dos incidentes", que está alcançando grande êxito de público. Abordando assuntos diversos, estas análises coincidem em sua tentativa de circunscrever um evento, re-

\footnotetext{
* Artigo recebido em: 18/10/2004. Autor convidado.

Este texto foi escrito a partir das questões suscitadas pelo livro de BREWER, John. A Sentimental Murder. Love and Madness in the Eighteenth Century. New York: Farrar, Straus and Giroux, 2004. 330 pages. (Uma versão desse texto foi publicada no The New York Review of Books).

1 Tradução de René Lommez, Revisão de Júnia Furtado.
} 
construí-lo, e relatá-lo como uma estória, usando toda sorte de técnicas narrativas; além de acompanharem sua repercussão e suas versões, através do tempo. Ao fazê-lo, tais estudos refletem o interesse recente dos historiadores pelo modo como se constrói e se significa a experiência da história. Ao mesmo tempo, suscitam indagações sobre os limites da reconstrução de um evento, e da utilização de artifícios em seu relato, resituando a discussão sobre a fronteira entre história, narração e ficção. Partindo do exame do livro A Sentimental Murder. [Love and Madness in the Eighteenth Century (BREWER, 2004)], no qual se aborda um crime passional ocorrido em Londres, em 1779, e suas repercussões, até 1950, o presente ensaio procura debater o panorama historiográfico criado pela emergência das análises de acontecimentos.

Palavras-chave História, Historiografia, História dos Incidentes

ABSTRACT Scandals, massacres, collapse, kidnappings: many themes that were associated with tabloids and crime novels have been the object of a great number of books of history, which have been garnering privileged space on the shelves of bookstores. This is a matter of the rise of a new historiographical genre, that of the "analyses of events," which is attaining great public success. Examining diverse subjects, these analyses coincide in their attempt to circumscribe an event, reconstruct it, and tell it as a story, using every sort of narrative technique, as well as following up its repercussions and versions throughout time. Such studies reflect in this practice the recent interest of historians in the way that the experience of history is constructed and made meaningful. At the same time, questions on the limits of reconstruction of an event, and the use of artifices in their narrating, are raised, re-situating the discussion on the border between history, narration, and fiction. Starting from an examination of the book $A$ Sentimental Murder. Love and Madness in the Eighteenth Century (BREWER, 2004), which relates a crime of passion that occurred in London, in 1779 and its repercussions up to 1950, the present essay attempts to debate the historiographical panorama created by the emergence of the analyses of events.

Key words History, Historiography, Incident History

O panorama da historiografia tem sofrido uma curiosa mudança. Entre a profusão de livros sobre os temas usuais - pais fundadores, cultura gay, a esfera pública, memória, o Holocausto, ecologia, globalização, escravidão, guerra e paz, sexo e gênero - um novo gênero emergiu. Ele 
se encontra disperso entre tantos sub-campos, que raramente tem sido notado; embora possa ser encontrado em todo lugar, mesmo nas principais estantes das livrarias, e no setor das "leituras obrigatórias" dos cursos universitários. Ele toma a forma de livros curtos, sobre acontecimentos dramáticos: assassinatos, escândalos, motins, catástrofes; o tipo de coisa que costumava ser a especialidade de tablóides e fascículos de romance policial, mas que agora aparece em livros de capa dura, portanto o selo das editoras universitárias.

Apesar de seu tema sensacionalista, esses livros representam uma séria aproximação para com a história. Eles merecem reconhecimento, e até, talvez, um selo de qualidade - uma appellation contrôlée. O melhor nome que posso dar a eles é o de "análises dos incidentes", pois, em toda sua variedade, compartilham uma característica comum: focam um incidente, relatam-no como uma estória, e então acompanham suas repercussões através da ordem social e até, em alguns casos, ao longo dos sucessivos períodos de tempo. Levantam questões atordoantes: como podemos saber o que realmente ocorreu? O que diferencia fato de ficção? Onde pode estar a verdade, entre interpretações divergentes? E deixam seus leitores com o "Efeito Rashomon":2 o passado, quando visto de perto, parece mais inescrutável que nunca.

O mais conhecido trabalho desse gênero, e aquele que serviu de modelo para muitos outros, é O retorno de Martin Guerre (1983), de Natalie Zemon Davis. Ele toma um incidente dramático - o julgamento de uma camponesa acusada de coabitar com um homem, que se passava por seu há longo tempo desaparecido marido -, e desenrola a sua narrativa, a fim de desnudar aspectos das relações de gênero e da vida camponesa, na França do século XVI. Ele também interpreta os sucessivos relatos do caso, desde os registros originais da corte até a recente versão cinematográfica. Natalie Zemon Davis trabalhou como consultora do filme, chegando, inclusive, a aparecer em um trecho dele. Mas, depois de ter colaborado com essa representação do evento, advertiu seus leitores que ela não poderia esclarecer o enigma que se encontrava em seu seio - as entranhas da história do casal Guerre -, e transformou seu livro num ensaio reflexivo sobre como um incidente pode ser conhecido, e sobre como ele pode si refletir, ao longo do tempo, por meio de sucessivas formas de comunicação.

Duas décadas depois, os historiadores ainda enfrentam problemas para chegar ao fundo de suas histórias. Mas o jogo é mais sério agora. Muitos dos incidentes dizem respeito aos mais negros aspectos do sé-

2 [NT.] Rashomon é um filme clássico de Akira Kurosawa sobre o Japão, o mais conhecido do diretor no ocidente, e o termo "Efeito Rashomon" traduz o fato de que os participantes de um evento são muito capazes de dar testemunhos contraditórios sobre o que aconteceu. 
culo XX, e a dificuldade acadêmica se combina com a fome de conhecimento histórico que sociedades inteiras têm sentido com crescente urgência. Enquanto os sobreviventes do passado reordenam suas memórias, as novas gerações querem saber a verdade sobre os traumas do passado.

O massacre de civis indefesos por soldados japoneses, durante a ocupação de Nanking (ou Nanjing, como hoje se costuma dizer), em dezembro de 1937, ilustra esta tendência. Quatro livros recentes retomaram o evento em grande detalhe, trabalhando com a hipótese de que, sendo ele corretamente compreendido, se revelará a natureza geral do imperialismo japonês. The Rape of Nanking (1997), de Íris Chang, dramatiza o massacre, frente a um público estrangeiro, leitor da língua inglesa, comparando-o com o Holocausto. Mas, o livro crucial, que desafiou os japoneses a confrontarem-se com o seu passado, foi The Nanjing Massacre, de Honda Katsuichi. Ainda que não houvesse sido publicado em inglês, até 1999, ele abriu um grande debate no Japão, desde a primeira vez que apareceu, como uma série de artigos de jornal, em 1971. Katisuichi, um jornalista veterano da Guerra do Vietnã, viajou à China, entrevistou sobreviventes, e reconstruiu as atrocidades com tanta precisão e paixão, que forçou seus leitores a se questionarem não apenas sobre os eventos de Nanking, mas também sobre a possibilidade de se imputar uma culpa coletiva pelas tragédias dos tempos de guerra.

Dois livros mais recentes - Nanking: Anatomy of na Atrocity, de Masahiro Yamamoto; e The Nanjing Massacre in History and Historiography, uma coletânea de ensaios, editados por Joshua Fogel — mostraram como o debate sobre estes acontecimentos continuou a reverberar na sociedade japonesa. Yamamoto tentou chegar a uma estimativa exata da escala do massacre, e argumentou que as tropas japonesas teriam matado cerca de 50.000 chineses, a maioria deles prisioneiros de guerra ou soldados potencialmente perigosos, disfarçados de civis. Esta estimativa desacreditou os revisionistas, que afirmavam que, virtualmente, nenhuma atrocidade havia ocorrido; mas ela de longe também não correspondia com a visão comum, que fixava o número de mortes entre 100.000 e 400.000, e enfatizava a condição indefesa das vítimas. Os colaboradores do volume de Fogel defendiam esta última interpretação, mas mudaram o fundamento do debate. Ao invés de se concentrarem primordialmente no próprio massacre, eles centraram a sua discussão no contexto da política do pós-guerra, e mostraram como a pesquisa histórica tinha sido influenciada pelas mudanças nas atitudes e memórias da guerra entre os japoneses em geral.

Essas duas preocupações - de um lado, com a reconstrução acadêmica de um evento, e, do outro, com a história de sua narração distinguem a nova história dos acontecimentos da antiga "história dos 
eventos", ou histoire événementielle, como era chamada pelos inimigos da Escola dos Annales, durante as décadas de 1950 e 1960. Operando nestes dois registros, os analistas dos incidentes têm sido capazes de mostrar a importância de momentos cruciais do passado.

Tal ênfase também os separa dos "micro-historiadores", seus parentes mais próximos entre os pesquisadores acadêmicos de hoje. Como foi desenvolvida, na Itália, por Giovanni Levi, Carlo Poni, Carlo Ginzburg, Edoardo Grendi, e outros, durante as décadas de 1970 e 1980, a microstoria se foca em pequenas unidades, tais como aldeias camponesas, nas quais é possível estudar fenômenos que não podem ser vistos a partir de níveis mais altos de abstração. Ela trata das coerções da vida cotidiana das pessoas comuns, e das estratégias que improvisavam para enfrentá-las. Visa à reconstrução sistemática dos mundos sociais, e mesmo o estabelecimento de inferências entre a micro e a macro escala da história. $^{3}$

Não a análise dos incidentes; pois esta se concentra em eventos, procura entender como as pessoas constroem sua experiência, e não o modo como elas se encaixam em estruturas. Na prática, portanto, a análise dos incidentes geralmente estuda os meios de comunicação, a opinião pública, e a memória coletiva. E ela encontra seu material mais rico nas narrativas de catástrofes, do tipo que aparece em jornais e nos processos dos tribunais.

Por exemplo, em Martyred Village: Commemorating the 1944 Massacre at Oradour-sur-Glane, Sarah Farmer estudou uma atrocidade militar: o massacre, pela Waffen-SS nazista, de 642 franceses inocentes, habitantes da cidade de Oradour-sur-Glane, em 10 de julho de 1944; e mostrou como narrativas diferentes sobre o evento revelavam fissuras na memória sobre a ocupação alemã. Em The Collaborator: The Trial and the Execution of Robert Brasillach, Alice Kaplan também reabriu as feridas deixadas pela ocupação. Ela narrou o processo de julgamento de um dos mais notórios colaboradores da França, Robert Brasillach, propagandista pró-nazista e poeta, mostrando como os argumentos de ambos os lados correspondiam às divisões internas da França do pósguerra; e como a execução de Brasillach por um pelotão de fuzilamento (depois do General de Gaulle ter se recusado a perdoá-lo) continua a ecoar de forma diferente entre os grupos políticos franceses, especialmente na extrema direita.

Bloody Saturday in the Soviet Union: Novocherkassk, de Samuel Baron, conta a estória do massacre de grevistas, em Novocherkassk, em 1 de junho de 1962; e também as tentativas de ocultar, ou explorar o even-

3 Ver: LEVI, Giovanni. Inheriting Power: The Story of na Exorcist. Chicago, 1988; REVEL, Jacques (org.), Jeux d'échelles. La micro-analyse à l'expériénce. Paris: 1996. 
to, desde as tentativas iniciais de acobertamento pelas autoridades comunistas, até as transmissões de programas vindos do ocidente no contexto da Guerra Fria, e as narrativas dos samizdat, ${ }^{4}$ que vieram à tona durante a Glasnost. An Absolute Massacre: The New Orleans Riot of July 30, 1866, de James Hollandsworth, persegue o tema do massacre na história norte-americana. Hollandsworth mostrou como a luta para dominar as eleições municipais, em New Orleans, causou a erupção de uma orgia de violência, que deixou, pelo menos, trinta e quatro mortos e uma centena de feridos, revelando que o racismo era o ingrediente principal na política da Reconstrução. An Ordinary Atrocity: Shaperville and Its Massacre, de Philip Frankel, trata de um incidente igualmente fatal: a matança de sul-africanos indefesos, na paróquia de Shaperville, em 21 de março de 1960; matança esta que se tornou o evento determinante na história do apartheid. Frankel perscrutou complexos e contraditórios testemunhos, a fim de explicar como o massacre aconteceu, e como versões opostas da matança se emaranhavam com as subseqüentes políticas da África do Sul.

A mais importante de todas as anatomias retrospectivas dos incidentes foi Neighbors: The Destruction of the Jewish Community in Jedwabne, Poland (2001), de Jan Gross. Por meio de uma meticulosa reunião de todas as evidências sobreviventes, Gross demonstrou que o massacre de 1.600 judeus, na cidade de Jedwabne, no final do verão de 1941, não foi orquestrado pelos nazistas. Ele foi executado, em sua maior parte, por poloneses que haviam vivido pacificamente com suas vítimas, por muitos anos. Em uma frase, que hoje se tornou famosa, Gross concluiu: "Metade da população de uma pequena cidade do leste europeu assassinou a outra metade". Sua conclusão provocou um profundo debate dentro da Polônia, pois os poloneses, como os japoneses, tendiam a se ver como as vítimas da guerra. O paralelo não vai muito longe, pois os japoneses eram agressores, enquanto os poloneses sofreram horriveis agressões, por duas frentes: a oeste, os nazistas, e a leste, os comunistas. Mas, Gross levantou evidências de que alguns poloneses, que fizeram o trabalho sujo para os nazistas, mais tarde foram recrutados pelos stalinistas. A Segunda Guerra Mundial devastou a Polônia de uma forma tão mais complexa e danosa do que aquela que é transmitida usualmente pela visão comum do pós-guerra, que posicionava de um lado as pobres vítimas nativas e de outro os opressores estrangeiros. Por meio de um meticuloso estudo de um único acontecimento, Gross obrigou todo um país a se confrontar com sua cumplicidade nas atrocidades que foram infligidas sobre a maior parte de seus habitantes, e a reavaliarem o curso de sua história, ao longo de todo o século XX.

4 [NT.] Samizdat: literatura impressa e distribuída clandestinamente durante a ditadura soviética. 
Apesar da variedade de seus temas, esses livros demonstram a preocupação comum que perpassa todas essas análises de incidentes: a ambição de contar estórias sobre acontecimentos com detalhes tão convincentes, que irão modificar a compreensão geral do passado. Muitos outros exemplos poderiam ser mencionados, mas nem todos tratam de grandes catástrofes, como os massacres. Dois livros recentes dizem respeito a incidentes na história do trabalho: a greve de Fulton Mills, em Atlanta em 1914, que expôs a situação dos trabalhadores na industrialização do sul; e a greve geral da indústria têxtil, em 1934, a qual mudou o programa do New Deal. Dois outros abordam eventos extraordinários, que testaram a coesão e estabeleceram a memória de pequenas comunidades: o desabamento de uma casa de congregação em construção, em Wilton, New Hampshire, em setembro de 1773; e o seqüestro de um vagão de um trem com órfãos entre duas pequenas cidades do Arizona, em 1904. Um estudo particularmente bem feito diz respeito a uma catástrofe que nunca aconteceu: o envenenamento do vinho servido durante a comunhão, na Catedral de Zurich, em 12 de setembro de 1776. Ainda que, ao cabo, tivesse se tornado claro que o vinho só estava estragado, a atrocidade daquilo que, num primeiro momento, pareceu ser uma tentativa sacrílega de assassinato em massa provocou um extenso debate sobre a natureza do mal, em pleno lluminismo Alemão.

Muitas histórias de incidentes tiraram seu material de processos judiciais que dramatizaram as questões sociais e políticas: o caso de um afro-americano condenado por assassinar uma operária branca, em uma fábrica de Chicago, em 1888; uma série de julgamentos e execuções ligadas ao assassinato de Sir Thomas Overbury, em 1613, que serviu como representação da política da Corte perante um amplo público, nos primórdios da Inglaterra moderna; o julgamento e a execução de dois minuciosos falsários burgueses, que jogaram com os dispendiosos hábitos de consumo dos novos ricos de Londres, nos anos de 1770; o caso de um criado que matou sua senhora, sacudindo a hierarquia social e os valores vitorianos em Brandon, Manitoba, em 1899; o julgamento de Beecher-Tilton, em 1875, que revelou traços de culpa no mundo moral e emocional dos pretensiosos reformadores de Nova York... Monografias sobre escândalos e processos judiciais aparecem quase todo mês, e representam apenas uma onda na maré cheia de análises de incidentes. Em um inventário dos livros resenhados, durante os três últimos anos, na The American Historical Review, identifiquei 32 trabalhos pertencentes a este gênero. E, uma investigação minuciosa da literatura histórica em outros países provavelmente aumentaria esse número em dúzias.

Essa tendência não deve ser confundida com estórias populares, que geralmente se atêm a incidentes espetaculares, a fim explorar seu apelo emocional. Ela representa um interesse recente, entre os historia- 
dores profissionais, pelo imediatismo da experiência, e pelos significados a ela atribuída. Mas, as análises dos incidentes tratam de uma tão perturbadora confusão de temas, que a uma questão inevitavelmente se impõe: de que vale tudo isso?

Esta questão pode não ter resposta. Mas, um caminho para se medir este tipo de história é observar como um mestre o trata. $O$ último livro do gênero, A Sentimental Murder, Love and Madness in the Eighteenth Century, ilustra os pontos fortes e fracos de uma análise de incidente, tal como foi desenvolvida por um dos maiores historiadores profissionais, John Brewer, um inglês instruído em Cambridge, que é atualmente professor no Califórnia Intitute of Technology.

Os primeiros livros de Brewer demonstraram seu talento para se encarregar dos principais temas da história inglesa, e para virar do avesso ou de cabeça para baixo suas interpretações tradicionais. Em Party ideology and Popular Politics at the Accession of Georg III (1976), ele questionou a visão dominante, associada a Sir Lewis Namier, de que a política, na Inglaterra do século XVIII, era um jogo de inclusão e exclusão restrito a uma pequena elite, e isento de conflito ideológico. Brewer mostrou que os ministros do Parlamento lutaram ferozmente por questões de princípios, e que seus conflitos recaíam, do Parlamento, sobre o mundo plebeu, com uma vigorosa cultura política própria. Em The Sinews of Power: War, Money and the English Estate 1688-1783(1989), ele debateu acerca da noção comum de que a Inglaterra georgiana era uma sociedade sub-governada, dirigida, nas províncias, por fidalgos amadores e, em Londres, por uma débil administração. Explicando como o governo levantava vastas somas de dinheiro através de tributos indiretos e taxas alfandegárias, ele demonstrou que o estado era um Leviatã, capaz de derrotar a França em uma série de guerras globais, e de criar um império mundial. Em The Pleasures of the Imagination: English Culture in the Eighteenth Century (1997), ele mostrou como um fenômeno, que era normalmente associado à Era Vitoriana, já teria começado a transformar a sociedade inglesa, no século XVIII. Ele operou as primeiras pesquisas sobre a ascensão do consumismo, a fim de produzir um grande quadro da vida cultural, retratando personagens da classe média num bem provido mundo das mercadorias.

A Sentimental Murder representa o abandono radical dessa tendência de escrever grandes livros sobre grandes temas. É uma história das coisas banais. Brewer conta a história de um assassinato que ocorreu do lado de fora do Convent Garden, em 7 de abril de 1779. Um recémordenado clérigo, James Hackman, atirou na amante do Conde de San- 
dwich, Martha Ray, quando ela estava a ponto de subir em sua carruagem. Ele, então, tentou disparar contra si mesmo, conseguindo apenas arranhar sua testa. Dois bilhetes em seu bolso revelaram que ele queria se casar com sua vítima, e que a recusa dela o induziu ao suicídio. No processo que se seguiu, o advogado de Hackman baseou sua defesa na idéia de insanidade temporária. O próprio Hackman testemunhou que longe de querer matar a mulher que ele amava, que na verdade tinha sido tomado por um "delírio momentâneo". (Brewer, 2004: 28) Ele se declarou pronto para morrer por seu crime, e foi estoicamente para a forca. O crime, o julgamento, e o enforcamento causaram um grande derramamento de tinta. Mas, o incidente foi rapidamente esquecido pelo público, preocupado com questões mais sérias, ligadas à Guerra de Independência Americana.

Por que reviver esta história hoje? Ela proporciona uma boa narrativa, é claro, e Brewer a conta bem. Ele dá vívidas descrições dos três protagonistas: Hackman, jovem, impetuoso, a síntese do "homem sentimental" do século XVIII; Ray, uma mulher já um pouco envelhecida (aos 35 anos, ela já tinha dado nove crianças a Sandwich), mas ainda bela e abençoada com uma voz angelical; e Sandwich, o derradeiro aristocrata, um velho (61 anos) libertino, e um político despótico, tão importante como Primeiro Lord do Almirantado, para se preocupar com sua reputação junta à plebe, mas não acima do uso de manobras escusas, para defender sua permanência no poder.

O crime e a punição contribuem para uma narrativa vívida. Nós recebemos a quantidade suficiente de detalhes: Hackman, na platéia, olhando fixamente para Ray, em seu camarote, durante a apresentação de Love in a Village, uma fábula sentimental sobre amantes desafortunados; a explosão de violência, do lado de fora do teatro; a morte imediata de Ray; Hackman tombado no chão: "Oh! Mate-me!... pelo amor de Deus, me mate!"; o interrogatório em Bow Street: mais súplicas por uma morte rápida; o julgamento: um pedido, desta vez, pela suavização da pena, por conta da insanidade temporária; o confronto com a morte na forca: Hackman estóico até o fim; sua prece final por Ray; a queda de seu lenço, como um sinal para o carrasco, de que ele estava pronto para ser "mandado para a eternidade".

Tendo pesquisado a fundo todas as evidências circunstanciais, Brewer inseriu anedotas (não muitas, mas nem tão poucas), na maior parte dos momentos narrativos. No julgamento, o beau monde incluía John Wilkies, que passou a James Boswell um bilhete, parabenizando-o por ter encontrado um assento perto da mais bela senhora. O cadáver de Hackman é dissecado e exibido publicamente no Surgeon's Hall, onde um jovem chefe da guarda, Henri Angelo, o viu e, indo se restabelecer num restaurante de carnes das proximidades, se vê incapacitado de 
comer. Nada é retocado, nada é inventado. Não temos conhecimento do interior dos pensamentos de Hackman, nem das paixões conflituosas de Ray. Brewer se recusa a ir além dos limites do que pode ser demonstrado pela documentação. Ele inclui 35 páginas de notas, e conta a história do assassinato em 27.

O texto da contra-capa resume o livro em duas sentenças: "Numa noite de abril, em 1779, Martha Ray, a bonita amante de um famoso aristocrata, foi morta por um tiro à queima roupa, por um jovem clérigo que, depois, tentou tirar a própria vida. Em vez disso, foi preso, julgado, e enforcado". Até isto poderia ser demais para uma história banal na Inglaterra hanoveriana. Por que Brewer dedicou tanta arte e tantos anos de estudo com um acontecimento que parece tão passageiro quanto um jornal diário?

Parte da resposta recai nos próprios jornais. Havia muitos deles em 1779: 5 diários e 8 tri-semanários, em Londres, e cerca de 40, publicados nas províncias - mais do que os existem hoje. Sendo mais exato, os jornais do século XVIII em nada se pareciam com a variante moderna. Eles não tinham manchetes, subtítulo, trabalho de arte, ou outras características familiares aos leitores de hoje. Pareciam panfletos, exceto pelo fato de que suas páginas eram normalmente divididas em colunas, e continham uma grande quantidade de pequenas notas, anunciando mercadorias à venda: daí seus nomes habituais, tais como Public Advertisere General Advertiser.

Os anúncios vinham acompanhados de novas estórias, mas as notícias pouco se distinguiam dos mexericos, e as estórias tomavam a forma de cartas enviadas por "correspondentes" anônimos. Repórteres profissionais, não existiam. Muitos dos correspondentes eram "escritores de parágrafos"5 ou mercenários, que circulavam entre os cafés, coletando anedotas, às quais descreviam em pedaços de papel, que vendiam para livreiros ou tipógrafos. Atuando como um editor primitivo, o livreiro ou o mestre de tipografia remendava os parágrafos, e produzia uma meia página de informações indigestas. Alguns parágrafos também vinham de leitores comuns, que queiram fofocar por impresso; de autores, que queriam promover seus livros; e de políticos, que desejavam denegrir oponentes e cultivar protetores.

Posto que tantos leitores eram escritores, e que a coleta de notícias ocorria sem a intervenção de profissionais, os jornais cresciam diretamente da cultura dos cafés, onde eram produzidos e consumidos. Longe de proporcionarem um quadro claro sobre o que de fato ocorreu, distorciam tudo o que ali se passava. Como Brewer observa, eles eram

5 [NT] "paragraph writes" pode ser traduzido literalmente como Redatores de Notas. 
"salas de espelhos nas quais visões parciais e opiniões tendenciosas eram refletidas de modo a parecerem 'fatos' transparentes. Assim que nelas entramos, temos de nos lembrar que nada era o que parecia". (BREWER: 2004, 45).

Essa observação nos traz para perto do que é o assunto do livro: não o que aconteceu em 7 de abril de 1779, mas sim como o assassinato foi divulgado por meio da mídia da época. Sandwich tinha influência o suficiente para se certificar de que a história, tal como ela apareceu nos diários, não causaria danos à sua reputação. Mas, até os jornais que eram hostis a ele não trataram do assassinato como um indício do comportamento escandaloso dos altos escalões. Ainda que o incidente tivesse fornecido detalhes sensacionalistas com perfeição, como cérebros espirrando sobre a calçada do centro de Londres, a imprensa não deu muito valor ao sangue, ao sexo e aos coágulos. Ao contrário, tocaram em tom menor, e orquestraram sua estória em torno de um único motivo: a sensibilidade.

Hackman apareceu nas reportagens como um homem de profunda sensibilidade e sentimentos nobres, tragicamente arrebatado por uma paixão avassaladora. Ray, o objeto de seu amor, não era uma cortesã, mas antes, uma vítima das circunstâncias, uma pobre moça com a alma pura, apesar de sua ligação com Sandwich. E, Sandwich ganhou um brilho sentimental: a perda de seu verdadeiro amor, a quem mantinha honradamente, como se fosse sua verdadeira esposa, deixou-o com o coração partido. Longe de se ater à violência, ao modo dos tablóides modernos, a imprensa cobriu a estória como se fosse um episódio de um folhetim sentimental comum.

Em 1779, os leitores ingleses estavam habituados a uma pesada dieta de sentimentos, servida por Richardson, Sterne, Arthur Young, Goethe, e Rousseau. Logo, seria natural que os escrevinhadores dos cafés retratassem Hackman como um primo do Werther, de Goethe, ou do Homem Sensível, de Henry Mackenzie, ao invés de Macheath. ${ }^{6}$ Mas a maré sentimental transbordou dos jornais para as revistas e os livros, onde ela não pôde ser tão eficazmente dirigida, pelos partidários de Sandwich.

Brewer dedicou três capítulos a cada um dos protagonistas, como apareciam em cada mídia impressa. Sandwich, nos livros e panfletos dos reformadores, foi dragado pela lama, tendo sido transformado num símbolo da decadência aristocrática e da corrupção política. Parte da sujeira veio de John Wilkes, o libertino radical que tinha contas pessoais a ajustar com Sandwich; mas a maior parte dela veio de uma vigorosa

6 [NT] Macheath: Personagem de John Gay, da Ópera dos mendigos. 
literatura de rua, que tratava de prostitutas e alcoviteiros. Eles, portanto, se dirigiam na direção oposta à da sensibilidade e, ao longo do caminho, manchavam a imagem de Martha Ray.

Esses periódicos a colocaram entre as más companhias - não do mesmo modo como faziam com as mulheres decaídas, descritas em trabalhos como Nocturnal Revels, uma viagem aos bordéis de Londres -; mas sim como as "semi-reprováveis", características de publicações de qualidade superior, como Town and Country Magazine. Uma "semi-reprovável" era uma meio-respeitável consorte de um próspero homem mundano e socialmente ativo; normalmente uma bela e jovem mulher, que ele colhera na obscuridade; dando-lhe um verniz de boas maneiras; instalando-a em sua residência, na cidade, como se fosse algo próximo a uma esposa legal. Na Town and Country Magazine circulava uma série de tête-à-têtes discretamente escandalosos, ilustrados com silhuetas fantasiosas dos aristocratas libertinos e das mulheres que eles mantinham. Ray e Sandwich figuraram com proeminência nesta e em outras revistas de variedades de literatura erótica, às quais Brewer examinou com humor e entusiasmo.

Hackman, no entanto, não se encaixava nesse contexto. Ele permaneceu sendo uma nobre figura - virtuoso, mas levado à loucura, pelo amor -, nos livros e artigos que apareceram depois de sua execução. 0 que o teria levado a cometer este crime? O mistério manteve a história viva, pois se desenvolvia em narrativas posteriores, mudando constantemente de forma e significado. The Case and Memoirs of James Hackman (1779), um best-seller que alcançou dez edições, fez de Hackman uma vítima, mais do que o executor da tragédia. O livro o descreve como um homem honrado, que perdeu seu coração para uma mulher fatal. Hackman havia sido iludido tanto por Ray, quanto por sua dama de companhia, Caterina Galli, que o levou a crer que Ray o tinha trocado por outro amante secreto. Assim como Otelo, ele teria matado a mulher a que amava, num delírio de paixão e desespero.

Love and Madness, a Story Too True (1780) levou o tema adiante, revertendo-o em um romance epistolar, e transformando Hackman herói romântico completo. As cartas foram escritas com tão elegante sensibilidade, que muitos leitores as tomaram como reais. Os dois livros foram lançados pelo mesmo editor, George Kearsley, que compreendeu perfeitamente o mercado, e usou todo tipo de manipulação publicitária para tirar proveito dele. Brewer apresenta a versão publicada da história de forma magistral, como explicou em seus textos. Ele mostrou quão briIhantemente jornalistas mercenários, autores grub-street, políticos cínicos, libertinos e negociantes escandalosos se entrelaçavam em uma cultura comum: uma versão inglesa das Ilusões Perdidas, de Balzac.

Isso torna a leitura fascinante, mas ela continua incessantemente. 
Brewer persegue cada variação da história, através do século XIX até a década de 1950. Temos a versão científica (Hackman sofria do fatal terceiro estágio da "erotomania"); a versão Wordsworthiana (uma longa exegese do poema The Thorn); a versão Vitoriana (o desprezo moralista pela decadência do século XVIII); a versão estética (o século XVIII como uma idade da elegância); a versão feminista (Ray, reclamada como uma heroína, é vítima do duplo padrão e do enfraquecimento geral da muIher); e muitos outros. Depois de 280 páginas de variações sobre o mesmo tema, o leitor, exausto, chega à conclusão, esperando alcançar uma revelação acerca da importância de tudo isso.

Esse leitor pode confessar que fechou o livro com um sentimento de desapontamento. Não há ninguém igual a Brewer para evocar a cultura da rua, na Londres do final do século XVIII; mas, quando ele se afasta disso, acaba por confirmar perspectivas pré-existentes. A versão romântica do assassinato torna a ser romântica; a vitoriana, vitoriana; e assim em diante. Nenhuma das elaboradas exegeses nos desafia a mudar o pensamento sobre nada de importante - nem mesmo a alusão final de Brewer, a qual nos traz de volta o problema de avaliar a análise de incidentes.

Brewer não pensa a si próprio como contribuindo para um novo gênero historiográfico. Ele poderia até objetar que tal gênero exista; e, se ele existisse, não teria obrigação de obedecer às suas convenções. Ele apresenta seu livro como um "experimento" (BREWER, 2004: 292), que nos ajudaria a sair da confusão inerente ao esforço de se separar fato de ficção. Fatos, ele insiste, não podem ser extraídos dos arquivos, como se fossem pepitas de realidade; e não podem ser combinados em uma narrativa que irá corresponder perfeitamente ao que realmente aconteceu. Escrever a História é contar uma estória e é, por isso, empregar muitos dos mesmos dispositivos retóricos que se usa na ficção. Nenhuma versão do assassinato de Ray pode ser definitiva. Suas variações sem fim expõem o artifício que há em cada relato de um evento, incluindo o seu próprio (capítulo 1).

Ok. Mas, já estávamos aí antes. Ranke, Michelet, e ate Namier (cujos ensaios literários são obras-primas) sabiam que precisavam contar com as técnicas literárias para comunicar sua compreensão do passado, e que essa compreensão histórica envolve mais interpretação que a habilidade de se fazer um texto se ajustar ao acontecimento, sem distorções. Brewer não traz contribuições filosóficas sobre a base epistemológica da história; ele ilustra o potencial da análise de incidentes. Sem saber, ele está fazendo isto; e fazendo bem. 
Com o quê se parece a análise de incidentes, quando mal feita? Ela pode ser sensacionalista; ela pode ser trivial; ela pode interpretar mal os eventos, ao cair em anacronismos; ela pode soar falsa. Brewer cita o livro Dead Certainties, de Simon Schama, como uma experiência da combinação de fato e ficção, à qual ele aparentemente tenta emular. (BREWER, 2004: 291) Mas Schama borda sua narrativa com materiais que ele próprio inventou; e ele falha ao não inserir sinais de advertência no texto, para que o leitor possa distinguir entre o que ele construiu e o que realmente ocorreu. Brewer não inventa nada, e documenta tudo. Como seus professores em Cambridge, ele é um bom empirista inglês.

O quê, então, distingue a análise de incidentes dos outros tipos de História? Não sua filosofia, mas seu tema, método, e ambição. Ela trata da concatenação de eventos, mais do que dos meros eventos em si, no esforço de encontrar seu significado - o que eles significavam para as pessoas que os vivenciaram, e para aqueles que mais tarde aprenderam sobre eles. Ela, portanto, se concentra nos relatos dos acontecimentos, e no modo como eles ecoaram através de vários meios de comunicação.

Agora que esses acontecimentos midiáticos dominam as notícias, uma história de como os acontecimentos se expressaram através da mídia poderia exercer alguma atração. Ela também pode abrir novos acessos para os velhos problemas do passado. Os historiadores geralmente falam da recuperação de vozes perdidas nos arquivos, quando se deparam com acontecimentos surpreendentes. Eles não escutam nada, é claro; apenas vêem alguns fragmentos da vida vivida há muito tempo, que acendem sua imaginação. F.M. Powicke, um venerável medievalista, da antiga escola de Oxford, descreveu sua experiência como um solavanco cognitivo:

Às vezes, quando trabalho sobre uma série de listas secretas e fechadas, tenho uma estranha sensação: os nomes mortos começam a ganhar vida. Essa sensação se parece mais com a experiência de se assentar na cadeira de alguém, e descobrir que esse alguém se sentou no gato. ${ }^{7}$

O efeito sentado-no-gato pode nos indicar a força que levou a "análise de incidentes" às principais estantes das livrarias. Se elas permanecerão ali, ou desaparecerão como outros modismos passageiros, ninguém pode dizer. Mas, sendo o livro de Brewer um sintoma de uma tendência mais ampla, parece que esse novo gênero deu uma nova vida à História acadêmica, trazendo-a ao alcance do público comum.

7 POWICKE, F.M. Ways of Medieval Life and Thought. Londres, 1950, p.67. Meus agradecimentos a Peter Brown, por esta referência, e outro a Paul Misraki, por muito mais. 


\section{BIBLIOGRAFIA}

ANDREW, Donna T.; MCGOWEN, Randall. The Perreaus and Mrs. Rudd: Forgery and Betrayal in Eighteenth-Century London. Berkeley; Los Angeles: University of California Press, 2001.

BARON, Samuel H.. Bloody Saturday in the Soviet Union: Novocherkassk, 1962. Stanford: Stanford University Press, 2001.

BELLANY, Alastair. The Politics of Court Scandal in Early Modern England: News Culture and the Overbury Affair, 1603-1660. New York: Cambridge University Press, 2002.

CHANG, Íris. The Rape of Nanking: The Forgotten Holocaust of World War II. New York: Basic Books, 1997.

CLARK, Charles E.. The Meetinghouse Tragedy: An Episode in the Life of a New England Town. Hanover: University Press of New England, 1998.

DALE, Elizabeth. The Rule of Justice: The People of Chicago versus Zephyr Davis. Columbus: Ohio State University Press, 2001.

DAVIS, Natalie. The Return of Martin Guerre. Cambridge, Mass.: Harvard University Press, 1983.

FARMER, Sarah. Martyred Village: Commemorating the 1944 Massacre at Oradour-surGlane. Berkeley; Los Angeles: University of California Press, 1999.

FOGEL, Joshua A.. The Nanjing Massacre in History and Historiography. Berkeley; Los Angeles: University of California Press, 2000.

FOX, Richard Wightman. Trials of Intimacy: Love and Loss in the Beecher-Tilton Scandal; Chicago: University of Chicago Press, 1999.

FRANKEL, Philip. An Ordinary Atrocity: Sharpeville and Its Massacre. New Haven: Yale University Press, 2001.

FREEDMAN, Jeffrey. A Poisoned Chalice. Princeton: Princeton University Press, 2002.

GORDON, Linda. The Great Arizona Orphan Abduction. Cambridge: Mass., Harvard University Press, 1999.

GROSS, Jan. Neighbors: The Destruction of the Jewish Community in Jedwabne, Poland. Princeton: Princeton University Press, 2001.

HOLLANDSWORTH, James G.. An Absolute Massacre: The New Orleans Riot of July 30, 1866. Baton Rouge: Louisiana State University Press, 2001.

IRONS, Janet. Testing the New Deal: The General Textile Strike of 1934 in the American South. Champaign: University of Illinois Press, 2000.

KAPLAN, Alice. The Collaborator: The Trial and Execution of Robert Brassillach. Chicago: University of Chicago Press, 2000.

KATSUICHI, Honda. The Nanjing Massacre: A Japanese Journalist Confronts Japan's National Shame / edited by Frank Gibney. Armonk, N.Y.: M. E. Sharpe, 1999.

KRAMER, Reinhold; MITCHELL, Tom. Walk Towasrds the Gallows: The Tragedy of Hilda Blake, Hanged 1899. New York: Oxford University Press, 2002.

KUHN, Clifford M.. Contesting the New South Order: The 1914-1915 Strike at Atlanta's Fulton Mills. Chapel Hill: University of North Carolina Press, 2001.

YAMAMOTO, Masahiro. Nanking: Anatomy of an Atrocity. Westport, Conn.: Praeger, 2000. 